\title{
A queue theory in the cross-polarization of antenna in satellite communication
}

\author{
Rio Mubarak ${ }^{1}$, Setiyo Budiyanto ${ }^{2}$, Putri Wulandari ${ }^{3}$, Fajar Rahayu ${ }^{4}$, Andi Adriansyah ${ }^{5}$, Mudrik \\ Alaydrus $^{6}$ \\ 1,2,5,6 Department of Electrical Engineering, Universitas Mercu Buana, Indonesia \\ ${ }^{3}$ Department of Electrical Engineering, Universitas Al Azhar Indonesia, Indonesia \\ ${ }^{4}$ Department of Electrical Engineering, Universitas Pembangunan Nasional "Veteran” Jakarta, Indonesia
}

\begin{tabular}{|c|c|}
\hline Article Info & ABSTRACT \\
\hline Article history: & \multirow{12}{*}{$\begin{array}{l}\text { Satellite communication is a telecommunications technique that uses satellites } \\
\text { as a connecting component, for example VSAT. In antenna installation, there is } \\
\text { an important process which is called the cross-polarization. Cross-polarization } \\
\text { is one process that cannot be released inside installation of VSAT antennas for } \\
\text { satellite communication. Sometimes, in this process, a user queue will occur. } \\
\text { Queuing theory explain the process is done and also calculate the other factors } \\
\text { that are in the process. By knowing queuing theory to the cross-polarization, it } \\
\text { will be easy to know the efficiency of queuing theory in the cross-polarization. } \\
\text { Based on the characteristics of the cross-polarization, user can be known the } \\
\text { queuing model that used and performance of the queuing system. The queuing } \\
\text { model for the cross-polarization, using kendall notation, M/M/1. Based on the } \\
\text { analysis that has been done; by using } 1 \text { server the value of service level }(\rho) \text { is } \\
0.67 \text {, using } 2 \text { servers }=0.33 \text { and } 3 \text { servers }=0.22 \text {. The waiting time in the queue } \\
\text { is longer if using } 1 \text { server which is } 0.67 \text { hours or } 40 \text { minutes. If a satellite } \\
\text { operator uses } 2 \text { servers, waiting time in the queue is } 25 \text { minutes and } 3 \text { servers is } \\
2.8 \text { minutes which means that there is almost no waiting time in the queue. }\end{array}$} \\
\hline Received Mar 10, 2020 & \\
\hline Revised Nov 29, 2020 & \\
\hline Accepted Jan 25, 2021 & \\
\hline & \\
\hline Keywords: & \\
\hline Communication & \\
\hline Cross polarization & \\
\hline Kendall notation & \\
\hline Queue theory & \\
\hline Satellite & \\
\hline & \\
\hline
\end{tabular}

This is an open access article under the CC BY-SA license.

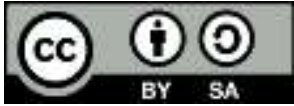

\section{Corresponding Author:}

Setiyo Budiyanto

Department of Electrical Engineering

Universitas Mercu Buana

Jl Meruya Selatan No.1, Kembangan-Jakarta 11650

Email: sbudiyanto@mercubuana.ac.id

\section{INTRODUCTION}

Queueing line is not a stranger things in this world and often happens in everyday life. In general, everyone ever waited in a waiting line for a service facility before getting the needed service. The queue occurs because the number of customers who come exceeds the number of services or capacity provided. So that, customers who come can not be served immediately because of the busy of service. The queue process itself is a process related to the arrival of a customer in a service facility, then waits in the queue, and finally left the service after being served [1]-[3]. The queueing theory is one of the branches of probability theory that was used initially to study traffic congestion that occurred on the telephone network in 1910. Furthermore, the theory developed to be used in service facilities, to handle service requests which changes up and down randomly. Besides that, the theory that developed can maintain a balance between service costs and costs required during queuing. At present the queue theory is more widely used in the banking, business and social. The examples of queuing theory are queuing models at restaurants, warehousing systems, banking systems, and hospital queues [4], [5]. The cross-polarization is applied not only in satellite communication. 
But also, in soliton-based fiber optic communication; dispersion managed optical transmission lines and radio-over fiber technologies in high traffic and congested networks that follow queuing models [6], [7]. Besides the communication engineering, medical imaging systems such as optical coherence tomography also make use of queuing mechanism for the enhanced data transfer to the data server [8]. In the telecommunications, especially satellite communication, there are also problems with queuing process. One of them is the queue to do cross-polarization on satellite communication. Cross-polarization is a carrier disturbance caused by antenna polarization being inaccurate to satellite polarization or it can also be caused due to an incorrect angular position of the feedhorn [9]. This will cause interference on other satellite communications which is on the contiguous frequency of that satellite antenna.

To overcome this, in the VSAT antenna installation process there is a process called antenna pointing. Antenna pointing process is the process of finding a peak signal that carried out by the earth station to receive signals from satellites. Where an installer will be faced with a cross-polarization. This cross polarization is carried out by adjusting the feedhorn angle in the parabolic antenna to transmit to satellites and see the best Eb/No signal [9]-[11]. This is done because each satellite's transponder has a reuse frequency with a different polarization or having a cross polarization isolation (CPI) value. An example is a Telkom 1 satellite owned by PT. Telkom, this satellite has 24 transponders which are divided into 12 vertical and 12 horizontal transponders [12]. Both transponder parts work on the same frequency. By differentiating the polarization, efficiency will be obtained thereby expanding the availability of transponders.

This cross-polarization is very important in the satellite communication, because if the process is not right, then the signal from other parties will interfere with the signal emitted and vice versa. So that, the data transmission technology can facilitates routing and discovery of the best path [13]. Therefore, determining the queuing model is very important in order to improve service quality by satellite operators. Especially in terms of the speed of the cross-polarization. This is because; the installers often must wait more than a day to cross-pollarization. This long queue process will certainly increase the cost to establish a VSAT antenna in satellite communications. So that with the right queue model, it can minimize the total cost, which is the costs while waiting for a queue and the cost due to adding service facilities.

\section{RESEARCH METHOD}

This research was conducted by taking quantitative data, that is data in the form of numbers. The quantitative data was obtained from the number of user arrivals when cross-polarization obtained from satellite XYZ companies. In addition, the data collection technique was also carried out with literature study. After that, writer will be analysing the queuing model based on user arrival patterns, operator service times and the number of operators available using FCFS queue discipline. So that later there will be obtained directional conclusions from the subject and can make decisions based on the results of the analysis obtained. Figure 1 shows the flow chart of research method for this research.

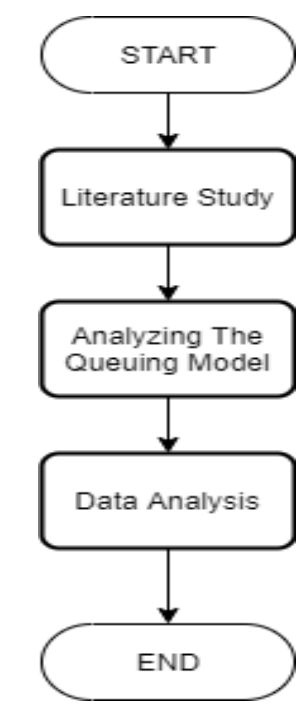

Figure 1. Flow chart of research method 


\subsection{Queueing theory}

Queuing is a process that results in waiting lines, either in the form of people or certain items, such as machines that require maintenance, orders that are waiting to be sent, or supplies of material to be used. Queues occur when the flow process there are obstacles caused by several factors or usually busy in the system. Queue analysis was first introduced by A.K. Erlang (1913) who studied fluctuations in demand for telephone facilities and delays in service delivery and subsequently developed in all fields [14], [15].

The application of queuing theory is usually found in customer service problems, such as queues at banks, restaurants and supermarkets. But besides that, the use of queuing theory is also applied in the fields of telecommunications. The queuing process can be discussed by using a mathematical analysis in the form of a random and exponential process [16]. Figure 2 shows the components in the queuing system that is arrival process, service time distribution, and number of servers, waiting process, customer population and service discipline [1], [17].

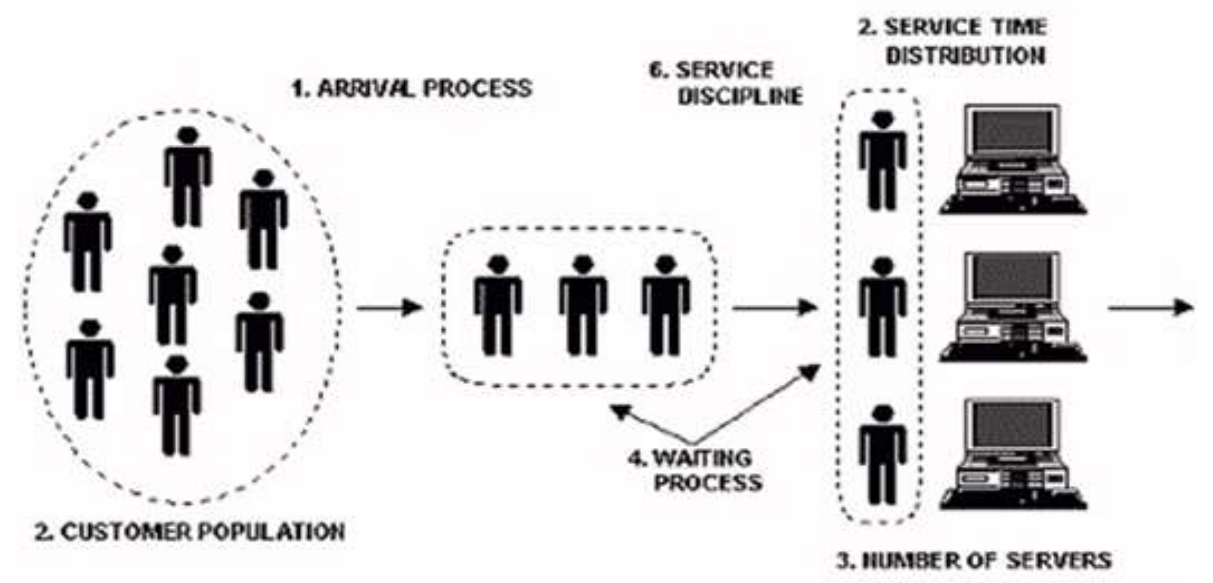

Figure 2. The component of the queue system [18]

The queuing process can be grouped into four basic structures according to the characteristics of service facilities, namely [18]-[21]: single channel single step (SCSS), multi channels single step (MCSS), single channel multi steps (SCMS), and multi channels multi steps (MCMS). In this study, the queuing model used is SCMS. Namely a service line structure that shows the existence of two or more services carried out sequentially [1], [19], [20]. After receiving services, the individual can leave the service area because there are still other individuals who must be served. In Figure 3 shows the queue structure using the SCMS queuing model. To prevent obstacles in the queue it can be done by adding service facilities to prevent or reduce the occurrence of queues. However, many factors must be considered from the service provider as will reduce the benefits that have been obtained.

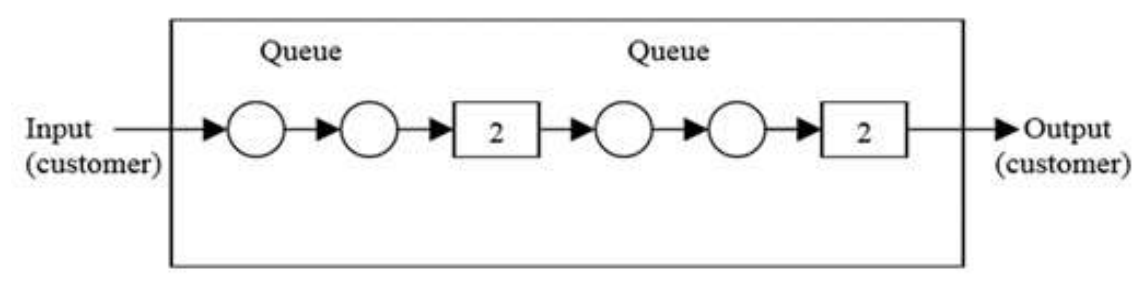

Figure 3. The structure of SCMS [17]

In the waiting process for cross-polarization requires a long waiting time or queue. One way to minimize waiting time is to research and apply queuing theory. So that users and satellite communication companies can estimate the time and cost needed precisely and accurately. The use of queuing models can also help design optimal operational systems. 


\subsection{Queueing model}

To measure an effective queuing model, four criteria are needed, namely optimizing the service system, determining service time, determining the number of queue channels, and the right number of services using queuing models. The queuing model can be written with mathematical notation called Kendall notation. Kendall notation has the format as follow [15], [19], [22], [23]:

$$
(\mathrm{a} / \mathrm{b} / \mathrm{c}):(\mathrm{d} / \mathrm{e} / \mathrm{f})
$$

Where:

$\mathrm{a}=$ Distribution of arrivals

$\mathrm{b}=$ Distribution of service time

$\mathrm{c}=$ Service facility or number of servers (series, parallel, station network)

$\mathrm{d}=$ Service or priority discipline (FCFS, LIFO, SIRO)

$\mathrm{e}=$ System size in queue (limited or unlimited)

$\mathrm{f}=$ Calling source (limited or unlimited)

It is known that the cross-polarization has a single channel multiple phases queuing system. Which mean, there is only one path to enter the service system but more than one (several) service stages are available and carried out sequentially. So, the queue model that can be applied is the M/M/1 model. Namely the queuing system which is a queue model of a server with the arrival of the Poisson distribution and the service time has an exponential distribution [24]. With FCFS service rules, the first-come customer is served and so on.

\subsection{Cross-polarization}

In the satellite telecommunications, there are two important components that needed the earth station and the satellite antenna itself. In business of satellite communication, this process requires very expensive costs. So that, it is not many countries or companies having their own satellites. Because of this, in one satellite, it will be used by many operators. To prevent interference between one satellite operator and another satellite operator, the cross-polarization regulation is enforced.

Cross-polarization is a standard or leveling used to measure the quality of lines that built with VSAT. This process is carried out to measure the angle of transmission propagation to the satellite. This is possible because the satellite transponder itself provides the reuse of a frequency in a cell with a different polarization [8]. The existence of cross-polarization will cause side lobe which will reduce the gain. In the cross-polarization, generally an installer will call the NOC and then contact the satellite operator and request the required frequency. The operator will monitor the carrier frequency that transmitted to the satellite and ask the installer to move and rotate the antenna feedhorn. The direction of the feedhorn on this parabolic antenna will determine whether an antenna works in vertical or horizontal polarization [25].

Cross-polarization is done to ensure that the signals emitted to the satellites are suitable. Moreover, it can be maximizing the direction of the antenna to the destination satellite, precisely to the transponder provided by the company. If the process is successful, then this satellite telecommunications network can be used. Generally, it will be connected from the modem to the router which will then be distributed again to a PC or laptop using a UTP cable. In the actual case, the server for help cross polarization is just one server. In this research will be done simulation using two or three servers.

\section{RESULTS AND DISCUSSION}

The cross-polarization will usually be done after installation of the VSAT is done. This process is done by looking at the best Eb/No values, on the modem that has been prepared. The first cross-polarization is to do the queue provided by the NOC at the central office with the time determined by the satellite owner (operator). When the queue at the satellite operator has been opened, each team will be given a maximum time of about 30 minutes from the satellite operator to carry out the cross-polarization. The team that will cross-polarization will be contacted by the NOC who has been connected via chat by satellite operators.

Furthermore, the satellite operator will ask that team to do antenna polarization by shifting the antenna direction to see the maximum beam antenna that will be obtained. If the maximum value is obtained, the satellite operator will tell the NOC to lock the antenna polarization. The next step is to adjust the elevation, which is the antenna beam angle to face up (sky). If it is maximum, the operator will notify the NOC again to lock the position. The last step is polarizing the feedhorn set by slowly shifting the feedhorn by forming the 3,9 or 12 a clock direction. If this last thing is done correctly, the operator will inform the NOC that the process is complete and pass the cross-polarization by giving a value of CPI. If the final result fails, then the cross-polarization must be repeated, and that team must queue again. 
Based on the analysis of data obtained over five days, from January $20^{\text {th }}-24$ th, 2020, the number of arrivals of users who will cross-polarization can be seen in Table 1, which are 29 users. The greatest number of users who come on Tuesday is 9 people, and the least is on Monday and Wednesday, which are 4 people. The data that obtained is data from observations made by the writer at XYZ company, when making a crosspolarization. The cross-polarization itself has certain times. Usually the satellite operators only provide two hours to the NOC so that the user cans cross-polarization. In one day, there are three times that can be used for cross-polarization services. For XYZ Company, the cross-polarization can be carried out at 08.00-10.00 WIB, 13.00-15.00 WIB and 18.00-20.00 WIB. If a user who has registered on that day failed crosspollarization, then that user must wait until tomorrow and enters the first queue list the next day.

From the results of this study, the time taken by the user to queue, to perform cross-polarization service, until completion can be seen in Table 2. In the table shows information on the minimum arrival time, maximum and average queue service time to cross-polarization. The length of the process is calculated from the user registers to the NOC until the cross-polarization process has been completed and is considered successful. In the queuing model with a single channel single stage is a model that has arrivals and departures by following the poisson distribution. Where there is one waiter, unlimited service capacity and arrivals. Before determining the queuing model, it is necessary to know whether the steady state condition is met or not. Steady State is a situation where the system does not depend on the initial state or can be mentioned if the level of usefulness is less than 1 [1], [12]. From the data contained in Table 1 and Table 2 it is found:

a) The average number of users that come $(\lambda)$ is 2 users every 60 minutes

b) The average service time is $(\mu)$ is 3 users every 60 minutes

c) The value of usefulness of service facilities $(\rho)$ which can be calculated using the formula [12], [26-30]:

$$
\rho=\frac{\lambda}{\mu}=\frac{2}{3}=0.67
$$

So, the value of service usefulness is 0.67 . Because $0.67<1$, the steady state can be fulfilled.

Table 1. Number of user arrivals in 5 days

\begin{tabular}{|c|c|}
\hline Day & Number of Users \\
\hline Monday (January, 20 ${ }^{\text {th }} 2020$ ) & 4 \\
\hline Tuesday (January, 21 $1^{\text {st }} 2020$ ) & 9 \\
\hline Wednesday (January, 22 ${ }^{\text {nd }} 2020$ ) & 4 \\
\hline Thursday (January, $23^{\text {th }} 2020$ ) & 5 \\
\hline Friday (January, 24 ${ }^{\text {th }} 2020$ ) & 7 \\
\hline
\end{tabular}

Table 2. Information on arrival and queue service time

\begin{tabular}{cccc}
\hline \multirow{2}{*}{ Day } & \multicolumn{3}{c}{ Average arrival and service process (minutes) } \\
& Min & Max & Average \\
\hline Monday & 35 & 84 & 54.25 \\
Tuesday & 27 & 1175 & 395.56 \\
Wednesday & 113 & 333 & 253.75 \\
Thursday & 32 & 276 & 168.8 \\
Friday & 202 & 1216 & 579.71 \\
\hline
\end{tabular}

If the arrival distribution, service distribution and factors affecting the queuing system are known, then the form of the queue mode can also be determined. It is known that the cross-polarization has a single channel-multiple phase type queuing system that is there is only one path to enter the service system with first come first served (FCFS) service discipline. However, the system is available in more than one service phase and is carried out sequentially. Therefore, the $\mathrm{M} / \mathrm{M} / 1$ queuing model formula can be used on this system is [1], [8], [9], [12]:

1. Average number of users in the system $\left(\mathrm{L}_{\mathrm{s}}\right)$.

$$
L_{s}=\frac{\rho}{1-\rho}=\frac{0.67}{1-0.67}=2.03 \approx 2 \text { user }
$$

2. Average number of users in the queue $\left(\mathrm{L}_{\mathrm{q}}\right)$. 


$$
L_{q}=\frac{\rho^{2}}{1-\rho}=\frac{0.67^{2}}{1-0.67}=1.36 \approx 1 \text { user }
$$

3. The average time users spend in the system $\left(\mathrm{W}_{\mathrm{s}}\right)$

$$
W_{s}=\frac{1}{\mu(1-\rho)}=\frac{1}{3(1-0.67)}=1.01 \text { hour }
$$

4. Average time the user spends in the queue $\left(\mathrm{W}_{\mathrm{q}}\right)$

$$
W_{q}=\frac{\rho}{\mu(1-\rho)}=\frac{0.67}{3(1-0.67)}=0.67 \text { hour }
$$

5. Server bustle level

$$
K=\rho \times 100 \%=0.67 \times 100=67 \%
$$

Based on the results of the performance measures obtained in these calculations, it appears that the average number of users in the system is 2 users. While the time spent by the user to cross-polarization per day is 1 hour. For the average number of users in the queue is 1 user with an average time spent by users in the queue is 0.67 hours (40 minutes). Then the queuing model analysis will be performed using POM for windows that can be seen in Table 3 .

From the Table 3, the analysis results using the POM for Windows program by using the average arrival $(\lambda)=2$, the average service $(\mu)=3$ and the number of services $s=1$, obtained the service utility $(\rho)=$ 0.67 , the average number of users in the queue $(\mathrm{Lq})=1.33$, the average number of users in the system $(\mathrm{Ls})=$ 2 , the average time customers spend in the queue $(\mathrm{Wq})=0.67$, and the average time customers spend in the system $(\mathrm{Ws})=1$. With the time given by the satellite operators, that they only open the cross-polarization as many as 3 sessions a day and only lasts about 2 hours per session. With an average time spent in service it is very possible for users to wait for more than 12 hours. From the K value (server bustle level) it can also be seen that satellite operators are quite busy in serving the cross-polarization.

The longer the user waits for the queue; of course, it will result in greater costs incurred. Therefore, to reduce the level of user density and streamline the cost and time of service, it is better for the satellite operator to repair the queuing system and improve the service of the cross-polarization. For example, by increasing the service opening time or by increasing the number of servers. Therefore, by using POM for Windows, the simulation by using increased the number of servers was done.

Based on Table 4, it can be seen that with the number of servers, both the simulation results and the actual results, are basically quite optimal. This can be seen from the performance of the queuing model obtained. By using 1 server the value of service level $(\rho)$ is 0.67 greater than using 2 servers $=0.33$ and 3 servers $=0.22$. However, the waiting time in the queue $\left(\mathrm{W}_{\mathrm{q}}\right)$ is longer if using 1 server which is 0.67 hours or 40 minutes. Whereas if satellite operator uses 2 servers, the waiting time in the queue (Wq) is 0.04 hours or around 25 minutes and 3 servers is 0.004 hours or around 2.8 minutes which means that there is almost no waiting time in the queue. So, according to the results of the performance model, to minimize costs due to the

\begin{tabular}{|c|c|c|c|c|c|}
\hline \multicolumn{2}{|l|}{ Input } & \multicolumn{4}{|c|}{ Output } \\
\hline Parameter & Value & Parameter & Value & Minute & Second \\
\hline Single-Channel System & & Average Server Utilization & 0.67 & & \\
\hline Arrival rate (lambda) & 2 & Average Number in the queue (Lq) & 1.33 & & \\
\hline Service rate $(\mathrm{mu})$ & 3 & Average Number in the System (Ls) & 2 & & \\
\hline Number of servers & 1 & Average time in the queue $(\mathrm{Wq})$ & 0.67 & 40 & 2400 \\
\hline & & Average time in the system (Ws) & 1 & 60 & 3600 \\
\hline
\end{tabular}
queue from the cross-polarization, the satellite operator can add the number of servers. Thus, the expected level of service will be more profitable in terms of cost.

Table 3. Result from POM for windows program to analysis 
Table 4. Queueing model performance

\begin{tabular}{cccc}
\hline \multirow{2}{*}{ Performance } & 1 (Actual) & S (Simulation) & 3 (Simulation) \\
\hline$\rho$ & 0.67 & 0.33 & 0.22 \\
$\mathrm{~L}_{\mathrm{q}}$ & 1.33 & 0.08 & 0 \\
$\mathrm{~L}_{\mathrm{s}}$ & 2 & 0.75 & 0.68 \\
$\mathrm{~W}_{\mathrm{q}}$ & 0.67 & 0.04 & 0.004 \\
$\mathrm{~W}_{\mathrm{s}}$ & 1 & 0.38 & 0.34 \\
\hline
\end{tabular}

\section{CONCLUSION}

From the research that has been done, it can be concluded that the cross-polarizarion queue in satellite communication can be notated using the $\mathrm{M} / \mathrm{M} / 1$ formula. The queuing system that used in the crosspolarization of antenna in satellite communication is Poisson distribution and the service time has an exponential distribution. With FCFS service rules, the first-come customer is served and so on. Based on research, it can be seen that by using 1 server the value of service level $(\rho)$ is 0.67 greater than using 2 servers $=0.33$ and 3 servers $=0.22$. Besides that, the waiting time in the queue $(\mathrm{Wq})$ is longer if using 1 server which is 0.67 hours. Whereas if satellite operator use 2 servers, the waiting time in the queue $(\mathrm{Wq})$ is 0.04 hours and 3 servers is 0.004 hours. According to the results of the performance model the best thing is to add the number of servers, at least 2 servers in the service process compared to 1 server. This can be seen from the time taken by the user to cross-polarization it can reach a waiting time of 12 hours.

\section{ACKNOWLEDGEMENTS}

This research was supported by Penelitian Tesis Magister, Ministry of Research and Technology/National Research and Innovation Agency, Indonesia. Based on research contract no: 064.ADD/LL3/PG/2020.

\section{REFERENCES}

[1] I. Franca, O. Agu, "Queuing Model For Effective Customer Service Delivery In The Banking Industry: A Study Of Union Bank PLC In Enugu Metropolis," International Journal of Management and Information Technology, vol. 7, pp. 1142-1154, 2013, doi: 10.24297/ijmit.v7i3.701.

[2] T. Fakokunde, A. Mustapha, M. Aremu, Mukaila, "Understanding the queuing theory for improved service delivery: an entrepreneurial-mindset approach," Ethiopian Journal of Business and Economics (The), vol. 6, no. 33, pp. 33-47, 2017, doi: 10.4314/ejbe.v6i1.2.

[3] A. Gabriel, "Queuing Theory: a model for Improving Customer Satisfaction in The Nigerian Banking Industry," University of Benin, Nigeria, 2011.

[4] C. Armero, S. Bayarri, "Queues," International Encyclopedia of the Social \& Behavioral Sciences (Second Edition). Pages 784-789, 2015.

[5] S. Ghimire, G. Thapa, R. Ghimire, S Silvestrov, Sergei, "A Survey on Queueing Systems with Mathematical Models and Applications," American Journal of Operational Research, vol. 7, no. 1, pp. 1-14, 2017, doi: 10.5923/j.ajor.20170701.01.

[6] M. R. Kumar, V. P. M. Pillai, and K. G. Gopchandran, "Performance analysis of a dispersion managed soliton transmission system," 3rd International Congress on Ultra Modern Telecommunications and Control Systems and Workshops (ICUMT), pp. 1-4, 2011.

[7] M. R. Kumar, V. P. M. Pillai, and K. G. Gopchandran, "Design and simulation of an optical communication system with dispersion managed RZ pulse," 3rd International Congress on Ultra Modern Telecommunications and Control Systems and Workshops (ICUMT), 2011, pp. 1-4.

[8] K. M. Ratheesh, L. K. Seah, and V. M. Murukeshan, "Spectral phase-based automatic calibration scheme for swept source-based optical coherence tomography systems," Physics in Medicine and Biology, vol. 61, no. 21, pp. 76527663, 2016, doi: 10.1088/0031-9155/61/21/7652.

[9] CommScope, "Microwave Communication Basics," CommScope, Inc. CO-109477.4-EN, 2017.

[10] The Eutelsat S.A. Systems Operations Guide (ESOG), "Antenna and VSAT Type Approval / Characterization," Eutelsat, 2019.

[11] A. Zamanifekri, "Ka-band integrated focal-plane arrays for two-way satellite communication," Eindhoven: Technische Universiteit Eindhoven. 2015.

[12] PT Telkom Indonesia (Persero) Tbk, “Annual Report 2019”, Jakarta, 2019.

[13] E. Ramadhan, A. Firdausi and S. Budiyanto, "Design and analysis QoS VoIP using routing Border Gateway Protocol (BGP)," 2017 International Conference on Broadband Communication, Wireless Sensors and Powering (BCWSP), 2017, pp. 1-4, doi: 10.1109/BCWSP.2017.8272556

[14] L. Green, "Queueing Theory and Modeling, " Graduate School of Business, Columbia University. New York, 2010. 
[15] N. Gans, G. Koole, A. Mandelbaum, A., "Telephone Call Centers: Tutorial, Review, and Research Prospects. manufacturing \& Service Operations Management," vol. 5, no. 2, pp. 79-141, 2003, doi: 10.1287/msom.5.2.79.16071.

[16] R. Sharma, "Mathematical Analysis of Queue with Phase Service: An Overview," Advances in Operations Research, 2014, doi: 10.1155/2014/240926.

[17] S. A. Mangkona, "Implementation of Queue Model for Measuring the Effectiveness of Suzuki Car Maintenance," World Journal of Business and Management, vol. 3, no. 1. 2018, doi: 10.31219/osf.io/yuqrt.

[18] R, Jain., "Introduction to Introduction to Queueing Theory Queueing Theory," Lecture Note, Washington University in Saint Louis, 2012.

[19] M, Gunes, "Queueing Models," Lecture Note, Freie Universitat in Berlin, 2019.

[20] H. Mehri, T. Djemel, H. Kammou, "Solving of Waiting Lines Models in the airport using Queuing Theory Model and Linear Programming The Practice Case : A.I.M.H.B," ffhal-00263072v2f. 2006.

[21] W. de Vries Jr, P. van Helsdingen, T. Borchert, "Services Marketing Management, an Introduction. First Edition," Noordhoff Uitgevers Groningen. The Netherlands, 2012.

[22] G. Sushil, G. Thapa, R. Ghimire, S. Silvestrov, "A Survey on Queueing Systems with Mathematical Models and Applications," American Journal of Operational Research, vol. 7, no. 1, pp. 1-14, 2017, doi: 10.5923/j.ajor.20170701.01.

[23] J. Sztrik, "Queueing theory and its applications-a personal view," Proceedings of the 8th International Conference on Applied Informatics, vol. 1, pp. 9-30. 2010, doi: 10.1145/2350716.2350717.

[24] I. Adan, J. Resing, "Queueing Systems," Department of Mathematics and Computing Science. Eindhoven University of Technology. The Netherlands. 2015.

[25] F. Didactic, "Telecommunications, Satellite Communications, Satellite Orbits, Coverage, and Antenna Alignment," pp. 452-455, 2011.

[26] S. Hasson Aljebori, Saad, "Simulation approach to model queuing Problems," 3rd International Union of Arab Statisticians Scientific Conference, Amman, Jordan, 2011.

[27] S. Budiyanto, M. Asvial, D. Gunawan, "Implementation Dedicated Sensing Receiver (DSR) in 3G - WiFi Offload," International Conference on Smart Green Technology in Electrical and Information Systems: Towards Greener Globe Through Smart Technology, ICSGTEIS 2014, pp. 37-42, 2014, doi: 10.1109/ICSGTEIS.2014.7038731.

[28] S. Budiyanto, A. Nugroho, "A new model of genetic zone routing protocol (GZRP): The process of load balancing and offloading on the UMTS - IEEE 802.11g hybrid networks," TELKOMNIKA (Telecommunication Computing Electronics and Control), vol. 15, no. 2, pp. 598-605, 2017, doi: 10.12928/TELKOMNIKA.v15i2.5633.

[29] S. Budiyanto, M. Asvial, D. Gunawan, "Improved Performance of Hybrid Algorithm for 3G - Wifioffload Networks," Jurnal Teknologi, vol. 8, no. 1, pp. 49-63, 2016, doi: 10.11113/jt.v78.8780.

[30] S. Budiyanto, H. C., Sihombing, Rahayu. F, "Depression and anxiety detection through the closed-loop method using DASS-21," TELKOMNIKA (Telecommunication Computing Electronics and Control), vol. 17, no. 4, pp. 2087-2097, 2019, doi: 10.12928/TELKOMNIKA.v17i4.12619.

\section{BIOGRAPHIES OF AUTHORS}
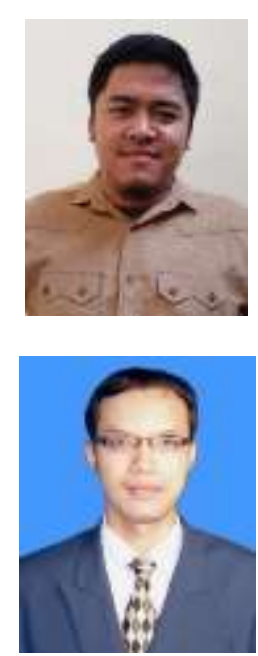

Rio Mubarak graduated from Electrical Engineering program at the Universitas Mercu Buana, Indonesia. He received his Bachelor's degree in Electrical Engineering from Universitas Al Azhar Indonesia in 2013. Currently he is working as Engineer Staff at Pasifik Satelit Nusantara. He has a strong interest in the field of telecommunication satellite.

Setiyo Budiyanto is an Associate Professor in Electrical Engineering, Universitas Mercu Buana. He received his Ph.D in Electrical Engineering, Universitas Indonesia (2016). Currently he is active as a Lecturer at Universitas Mercu Buana, Jakarta (Indonesia). He conducts some research in the fields of Digital-Advanced Wireless Communication (D-AWC) 


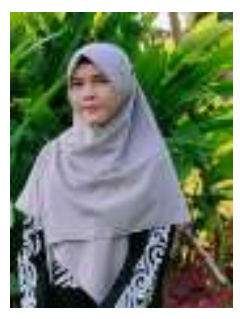

Putri Wulandari graduated from Universiti Brunei Darussalam-Brunei Darussalam in September 2016 with a Master's of Science in Computer Science. She received her Bachelor's degree in Electrical Engineering from Universitas Al Azhar Indonesia in 2012. She is currently a Lecturer in the Department of Electrical Engineering at Universitas Al Azhar Indonesia. Her research interests include Renewable Energy, Telecommunication Satellite, Biomedical Engineering and Antenna.

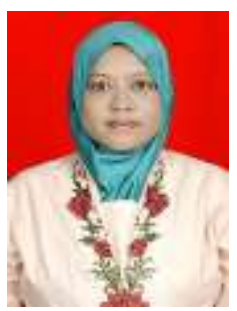

Fajar Rahayu I. M received her Master of Engineering (MT) degree in Electrical Engineering, Universitas Indonesia. She currently teaches at Universitas Pembangunan Nasional "Veteran", Jakarta (Indonesia).

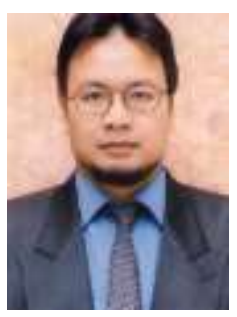

Prof. Dr. Andi Adriansyah is a professor in Electrical Engineering. He completed his undergraduate education in Electrical Engineering, Universitas Indonesia, Indonesia, in 1994. Then his master's and doctoral education was completed at Universiti Teknologi Malaysia, Malaysia, in 1998 and 2007, respectively. Currently, He is active as a Postgraduate lecturer at Universitas Mercu Buana, Indonesia and conducts some researchs in the fields of mechatronics, robotics, control and automation, artificial intelligence and the Internet of Things (IoT).

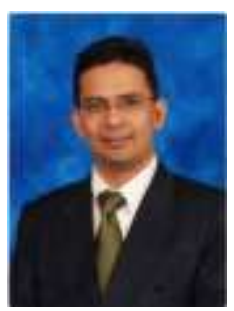

Mudrik Alaydrus Professor - Department of Electrical Engineering, Universitas Mercu Buana, Indonesia. 